\title{
Attenuation of the Effects of Corticosteroids on Declarative Memory with Lamotrigine
}

\author{
E Sherwood Brown*,', Justin Wolfshohl', Mujeeb U Shad', Miguel Vazquez ${ }^{2}$ and I Julian Osuji' \\ 'Department of Psychiatry, University of Texas Southwestern Medical Center, Dallas, TX, USA; ${ }^{2}$ Department of Internal Medicine, University of \\ Texas Southwestern Medical Center, Dallas, TX, USA
}

\begin{abstract}
An extensive animal literature suggests that excessive corticosteroid exposure is associated with changes in memory and the hippocampus. Agents that decrease glutamate attenuate corticosteroid effects on the hippocampus. Minimal data are available on preventing or reversing corticosteroid effects on the human hippocampus. We previously reported that open-label lamotrigine was associated with significant improvement in declarative memory in corticosteroid-treated patients. We now examine the impact of 24 weeks of randomized, placebo-controlled lamotrigine therapy on declarative memory (primary aim) and hippocampal volume (secondary aim) in 28 patients ( $n=16$ for lamotrigine, $n=12$ for placebo) taking prescription corticosteroids. All participants with data from at least one postbaseline assessment ( $n=9$ for lamotrigine, $n=1 \mid$ for placebo) were included in the analysis. Declarative memory was assessed with the Rey Auditory Verbal Learning Test (RAVLT) at baseline and weeks 12 and 24. Hippocampal and total brain volumes were manually traced from MRI scans obtained at baseline and week 24 . On the basis of an ANCOVA analysis, total words learned on the RAVLT at exit were significantly greater in the lamotrigine group $(n=8$, missing data or dropouts $n=8)$ compared to the placebo group $(n=11$, dropout $n=1)$. RAVLT scores in the lamotrigine group increased from mildly impaired to average range. Hippocampal volume changes were small in both lamotrigine $(n=7)$ and placebo $(n=7)$ groups during the 24-week assessment period and between-group differences were not significant. Results suggest that lamotrigine may improve declarative memory in patients taking prescription corticosteroids although differential dropout rate in the two groups is a concern.

Neuropsychopharmacology (2008) 33, 2376-2383; doi:I0. I038/sj.npp. I 30 I627; published online I4 November 2007
\end{abstract}

Keywords: corticosteroids; lamotrigine; memory; hippocampus

\section{INTRODUCTION}

An extensive literature suggests that stress or excessive corticosteroid exposure is associated with changes in memory and hippocampal structure in animals (Magariños et al, 1997; Vyas et al, 2002; Uno et al, 1989, 1994; Sapolsky et al, 1990; Lupien and McEwen, 1997). Leverenz et al (1999) did not find overall between-group differences in total hippocampal or subfield volumes, neuronal number, or density in older macaques given oral hydrocortisone for 12 months. However, they found a strong negative correlation between cerebrospinal fluid (CSF) cortisol levels and hippocampal volume $(r=0.83, p \leqslant 0.05)$ (Leverenz et al, 2003). In animals, agents that decrease glutamate release or enhance serotonin reuptake attenuate the effects of corticosteroids on the hippocampus (Magariños and McEwen, 1995; Magariños et al, 1996, 1999; Luine et al, 1994; Conrad et al, 1996; Watanabe et al, 1992). Examining

*Correspondence: Dr ES Brown, Department of Psychiatry, University of Texas Southwestern Medical Center, 5323 Harry Hines Boulevard, Dallas, TX 75390-8849, USA, Tel: + I 214 645-6950, Fax: + I 214 645-695 I, E-mail: Sherwood.Brown@UTSouthwestern.edu

Received 16 May 2007; accepted 21 September 2007 the effects of corticosteroids on the human hippocampus is challenging since humans cannot ethically be administered corticosteroids for extended periods of time. Therefore, a much smaller human literature on the effects of corticosteroids on the hippocampus is available. Acute administration of exogenous corticosteroids in humans is associated with decline in declarative memory performance (Newcomer et al, 1999; de Quervain et al, 2000; Brown et al, 2006; Bender et al, 1988). Patients with Cushing's disease, and cortisol elevations secondary to ACTH-producing pituitary tumors, have memory impairment (Mauri et al, 1993; Starkman and Schteingart, 1981) and hippocampal atrophy (Starkman et al, 1992) that are at least partially reversible a mean of 17 months after surgery to normalize cortisol levels (Starkman et al, 1999, 2003).

We reported that patients receiving long-term corticosteroid therapy had significantly poorer declarative memory performance, lower temporal lobe levels of $\mathrm{N}$-acetyl aspartate (NAA), and smaller hippocampal volumes than controls with similar medical histories not taking corticosteroids (Brown et al, 2004). However, another report did not find a reduction in NAA levels in patients taking corticosteroids (Khiat et al, 2001), and no changes in hippocampal volume (Hajek et al, 2006) or post-mortem 
histology (Lucassen et al, 2001) were found during corticosteroid exposure that was of much shorter duration than in our report (Brown et al, 2004).

We previously reported significant improvement in declarative memory in corticosteroid-treated patients given open-label lamotrigine (Brown et al, 2003), an antiseizure and mood-stabilizing medication that inhibits glutamate release through modulation of high voltage-activated calcium currents (Stefani et al, 1997; Pisani et al, 2004; Wang et al, 2001) and sodium channels (Stefani et al, 1997; Rogawski and Loscher, 2004; Sitges et al, 2007; Remy et al, 2003). In this report we examined the impact of 24 weeks of randomized, double-blind, placebo-controlled treatment with lamotrigine on declarative memory in patients receiving prescription corticosteroids as the primary aim. A secondary aim was to examine whether between-group differences in hippocampal volume could be detected following 24 weeks of lamotrigine therapy.

\section{METHODS}

\section{Participants and Study Medication}

A total of 28 medically stable outpatients receiving chronic oral corticosteroid therapy participated in a 24-week randomized, double-blind, placebo-controlled trial of lamotrigine. The enrollment period was from August 2002 through March 2005 with the final week-24 assessment in October 2005. Participants were enrolled from clinics in the UT Southwestern Medical Center that treat patients with chronic oral corticosteroid therapy. Assessments and interventions were conducted at the Psychoneuroendocrine Research Program clinic at UT Southwestern. Inclusion criteria were age of 18-65 years and corticosteroid therapy of at least $7.5 \mathrm{mg}$ of prednisone equivalents daily for at least 6 months. Exclusion criteria were drug or alcohol abuse or dependence, illnesses associated with hippocampal atrophy or with significant CNS involvement (seizures, closed head injury with loss of consciousness, brain tumors, multiple sclerosis), history of a depressive disorder not related to corticosteroid therapy, bipolar disorder, schizophrenia, or posttraumatic stress disorder on a structured clinical interview, mental retardation, dementia or other severe cognitive impairment, pregnant or nursing women, severe or life-threatening medical illness which would make completion of study unlikely, history of allergic reaction or other contraindications to MRI, or lamotrigine therapy. All participants signed an IRB-approved informed consent form. Randomization to treatment group was accomplished using a random number generator at www.randomizer.org by a staff member with no patient contact. Lamotrigine or identical appearing placebo was initiated at $25 \mathrm{mg}$ per day for 2 weeks, increased to $50 \mathrm{mg}$ per day for 2 weeks, and then increased in $50 \mathrm{mg}$ per day increments weekly to a dose of $400 \mathrm{mg}$ per day at week 10 using a fixed dosing schedule unless side effects required a slower titration or dose reduction. To minimize any possibility of rater bias, dose reductions or slower titrations were made by the study physician in a blinded fashion after the research assistant had collected research data for that assessment. The study was registered at clinicaltrials.gov.

\section{Diagnostic and Declarative Memory Assessment}

A structured clinical interview for DSM-IV (SCID-CV) (First et al, 1995) was administered at baseline to assess past and current psychiatric diagnoses that were exclusionary. The Rey Auditory Verbal Learning Test (RAVLT) (Schmidt, 1996) was administered at baseline and weeks 12 and 24 follow-up, by a blinded staff member, with extensive training and experience to assess declarative memory, using alternate versions (administered in a randomized order) to minimize practice or learning effects. The RAVLT consists of 15 nouns read aloud for five consecutive trials with each trial followed by a free-recall trial. The total score is the total number of words recalled through the five trials. Normative RAVLT $T$-scores controlling for age are reported.

\section{MRI and Procedures}

Structural and functional magnetic resonance (MR) images of the brain were obtained at baseline and week 24 followup visits. MR images were acquired on a General Electric Horizon LX NV/i 1.5 Tesla scanner (General Electric Medical Systems, Milwaukee, WI) using the standard GE quadrature birdcage RF head coil. To avoid large head motions, each subject's head was immobilized with tightly fitting foam padding and a head strap that was fastened across the forehead. High-resolution T1 images of the entire brain (3D Spoiled Grass (SPGR) pulse sequence: $\mathrm{TR}=40 \mathrm{~ms} ; \mathrm{TE}=5 \mathrm{~ms} ;$ flip angle $=40^{\circ} ;$ matrix $=256 \times 256$; $\mathrm{FOV}=24 ; \mathrm{PFOV}=0.75, \mathrm{NEX}=1$; slice thickness $=1.7 \mathrm{~mm}$ ) were acquired during the same scan session for each participant.

\section{Structural MRI Volumetric Analysis}

Anatomical measurements were conducted by two trained and reliable raters and were supervised by one of the authors (MUS), who, following training at Dr MS Keshavan's laboratory at the University of Pittsburgh, has conducted structural imaging analysis at the University of Pittsburgh and UT Southwestern since 2000 (Shad et al, 2004, 2006). BRAINS2 software (Magnotta et al, 2002) was used to conduct the measurements. Both raters were blind to participant identity, study group assignment, and clinical data. The scans were analyzed in pairs (baseline, week 24) for each participant with the rater unaware of the order. Inter-rater reliabilities (intraclass correlations; $n=10$ ) were 0.92 for total brain volume (TBV), 0.91 for right hippocampus, and 0.94 for left hippocampus.

The hippocampus was defined as follows: the superior boundary of the hippocampus is formed by the inferior horn of the lateral ventricle, the inferior boundary by the white matter of the parahippocampal gyrus, the lateral border by the white matter of the temporal stem, and the medial border by the interpeduncular cistern of the white matter. Since it is difficult to differentiate between amygdala and hippocampus complex (Shenton et al, 2001, 2002), we used the method described by Keshavan et al (2002) which uses the anterior wall of mammillary bodies as the first slice and slice no. 78 (or the slice where the superior and inferior colliculi are fused) as the last slice to measure the hippocampus. 
All planes were used to trace the hippocampus with most tracing done in the coronal plane because it had the best resolution. Sagittal and axial planes were used as references (Cook et al, 1992; Duvernoy 1999, 2005). Tracing began at the tail of the hippocampus and proceeded rostrally in the coronal plane. The caudal-most extent of the tail of the hippocampus is located where the end of the fornix column is at its greatest length, where it abuts the structure. In this slice, the subsplenial gyrus should be visible immediately superior to the hippocampal formation. The parahippocampal gyrus should be visible immediately inferior to it (Cook et al, 1992). Moving anteriorly, the thalamus separates the hippocampal formation from the fornix, and replaces the subsplenial cortex as the structure immediately superior to it. The alveus, a thin lining of white matter, borders the hippocampal formation dorsally and separates it from the hippocampal fissure.

A few slices before the head of the hippocampus come into view, the choroid plexus becomes visible and is superior to the alveus. Moving closer to the head of the hippocampus, the uncal gyrus replaces the choroid plexus as the structure immediately superior to the alveus. Paging rostrally in the coronal plane, the uncal gyrus thickens and blends in with the amygdala. Paging through the coronal slices rostrally, as the head of the hippocampus comes more into view, the amygdala becomes bigger. While tracing the hippocampal head, the alveus continued to be the critical structure that effectively differentiated the hippocampus from the amygdala.

Total brain volume, defined as brain, dura, ventricular and extraventricular CSF, brainstem, and cerebellum, was assessed by manual tracing of coronal slices along the inner border of the inner table of the skull (Gilbert et al, 2001).

All hippocampal volumes were adjusted for TBV by using the formula right or left hippocampal volume/TBV $\times 100$. TBV was measured using protocol described by Gilbert $e t$ al (2001), which includes combined volume of the cerebral hemispheres, cerebellum, and the brainstem.

\section{Statistical Analyses}

In our open-label pilot study a baseline-to-exit change of $10.0 \pm 7.8$ on the RAVLT was observed (Brown et al, 2003). On the basis of these data, a significant level of $p=0.05$, and assuming the same standard deviation as with lamotrigine but no mean change in the placebo group, a sample of 10 per group would provide $80 \%$ power and 13 per group $90 \%$ power to detect between-group differences in a randomized, controlled trial. Thus, the current study $(n=28)$ was adequately powered for the primary aim.

For the RAVLT (primary aim) a one-way ANCOVA, using baseline RAVLT scores, current corticosteroid dose, duration of corticosteroid therapy, and years of education as covariates and gender as a fixed factor, was conducted to compare total scores between groups at exit on the intentto-treat sample (those with week 12 or week 24 assessments). For hippocampal volume/TBV ratio (secondary aim) a one-way ANCOVA, using baseline hippocampal volume, current prednisone dose, duration of corticosteroid therapy, and years of education as covariates, and gender as a fixed factor was conducted to assess exit left and right hippocampal volume/TBV between groups in those with exit MRI data (week 24). Based on the KolmogorovSmirnov test, the data were normally distributed.

Correlations between baseline and baseline-to-exit change in RAVLT scores and hippocampal volume and age, current corticosteroid dose, duration of corticosteroid therapy, and level of education were explored using Pearson's correlation coefficient.

\section{RESULTS}

A total of 28 participants were randomized $(n=16$ lamotrigine and $n=12$ placebo) with 20 participants ( $n=9$ lamotrigine and $n=11$ placebo) returning for at least one postbaseline RAVLT assessment (week 12 and/or 24) (intent-to-treat sample). One participant had missing RAVLT data leaving 19 participants $(n=8$ lamotrigine and $n=11$ placebo) in the sample used for the analysis. Data at the week 24 assessment (end of study) were available on 18 participants ( $n=8$ lamotrigine and $n=10$ placebo). Early dropouts and the intent-to-treat sample were similar at baseline, with the exception of percentage of men and left hippocampal volumes that showed trends toward betweengroup differences (Table 1). The lamotrigine and placebo groups were similar on demographic and other baseline characteristics (Table 2). Concomitant medications were numerous in both early dropouts and those who returned for at least one postbaseline assessment (Table 1), and consisted of immunosuppressants (7 (88\%) vs 16 (80\%)), antihypertensives $(6(75 \%)$ vs $16(80 \%))$, antacids $(6(75 \%)$ vs $18(90 \%))$, analgesics (1 (13\%) vs $8(40 \%))$, antidepressants (3 (38\%) vs $4(20 \%))$, vitamin/mineral supplements (4 (50\%) vs $13(65 \%))$, sedative/hypnotic/anxiolytics (1 (13\%) vs $1(5 \%)$ ), antipsychotics (for sleep and other adjunctive therapy, not psychosis) (1 (13\%) vs 1 (5\%)), muscle relaxants (1 (13\%) vs $2(10 \%)$ ), anticonvulsants (not prescribed for seizures) (0 (0\%) vs $1(5 \%))$, antiemetics (1 (13\%) vs $0(0 \%))$, xanthine oxidase inhibitors (1 (13\%) vs $1(5 \%))$, statins $(2(25 \%)$ vs $5(25 \%))$, antimicrobials (2 (25\%) vs $5(25 \%))$, antihyperglycemics (4 (50\%), vs $2(10 \%))$, antihistamines (1 (13\%) vs $3(15 \%))$, estrogen supplementation $(0(0 \%)$ vs $1(5 \%))$, carbonic anhydrase inhibitor (0 (0\%) vs $1(5 \%))$, and erectile dysfunction medication (0 (0\%) vs 1 (5\%)). Concomitant medications in the treatment groups (lamotrigine $v s$ placebo) in the intentto-treat sample were also similar in number (Table 2) and consisted of immunosuppressants (7 (78\%) vs 9 (82\%)), antihypertensives (8 (89\%) vs $10(91 \%))$, antacids (5 (56\%) vs $3(27 \%))$, analgesics $(4(44 \%)$ vs $4(36 \%))$, vitamins/ mineral supplementation (5 (56\%) vs $8(73 \%))$, antidepressants (3 (33\%) vs $1(9 \%))$, muscle relaxant $(2(22 \%)$ vs $0(9 \%)$ ), sedative/hypnotic/anxiolytic (1 (11\%) vs $0(0 \%))$, statins (1 (11\%) vs $4(36 \%))$, antihyperglycemic (0 (0\%) vs (2 (18\%)), antihistamines (1 (11\%) vs $2(18 \%))$, estrogen supplementation $(0(0 \%)$ vs $1(9 \%))$, antipsychotic $(1(11 \%)$ vs $0(0 \%))$, xanthine oxidase inhibitor $(0(0 \%)$ vs $1(9 \%))$, anticonvulsant $(1(11 \%)$ vs $(0(0 \%))$, estrogen supplementation $(0(0 \%) v s 1(9 \%))$, antimicrobial (2 (22\%) vs $3(27 \%))$, carbonic anhydrase inhibitor (0 (0\%) vs 1 (9\%)), and erectile dysfunction medication (1 (11\%) vs 0 (0\%)). Changes in concomitant medications defined as any 
Table I Demographic Information for Those with a Week 12 or Week 24 Assessment $(N=20)$ and Early Dropouts $(N=8)$

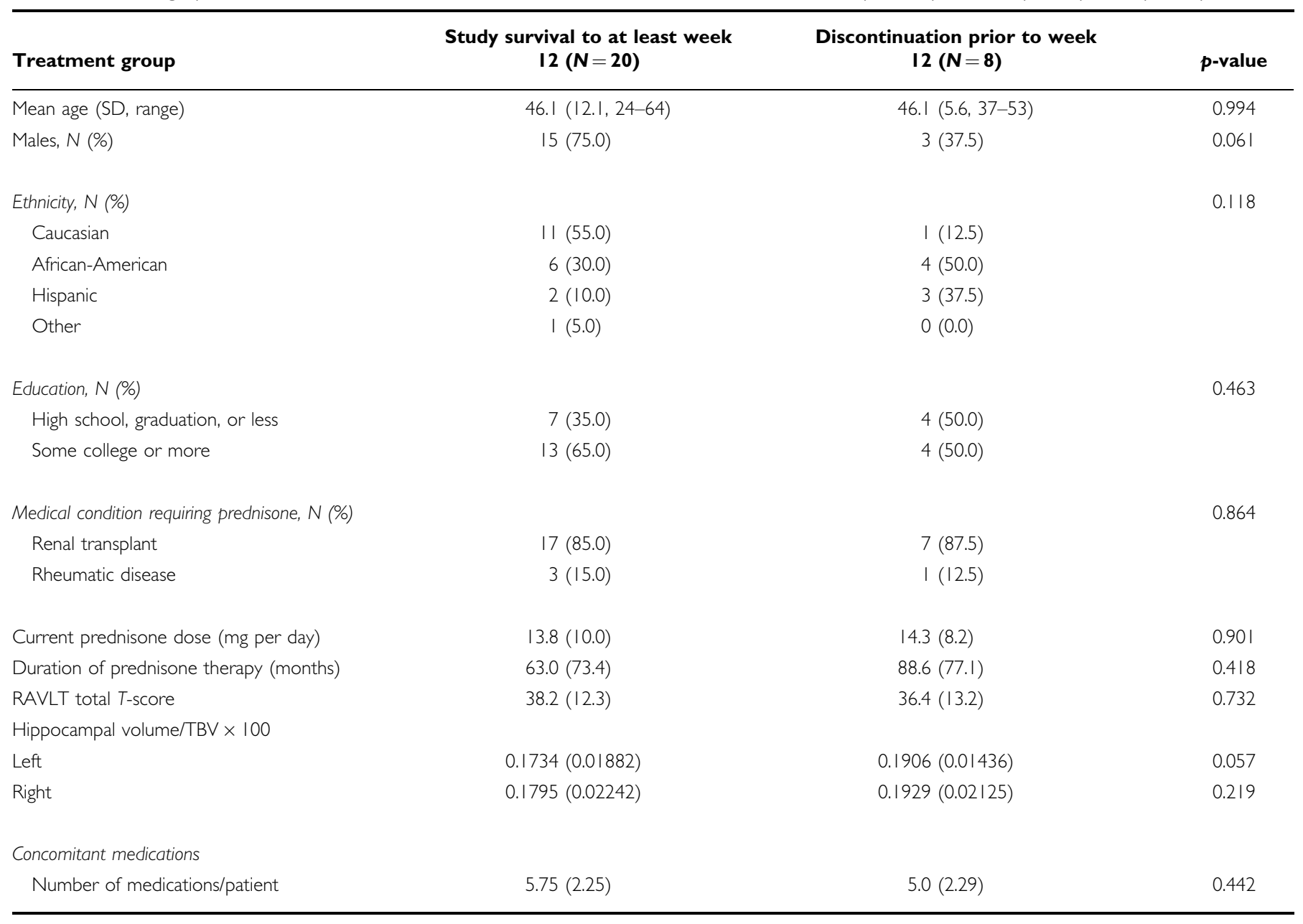

Abbreviations: RAVLT, Rey Auditory Verbal Learning Test; SD, standard deviation; TBV, total brain volume

addition, discontinuation or change in dose or frequency were similar in the two groups (Table 2).

The mean baseline dose of corticosteroids was numerically, but not statistically significantly, higher in the lamotrigine group (Table 2). Exit corticosteroid dose (16.7 $\pm 16.7 \mathrm{mg}$ per day for lamotrigine $v s 9.4 \pm 3.8 \mathrm{mg}$ per day for placebo) was not significantly different between groups $(p=0.175)$. The baseline-to-exit difference in corticosteroid dose was also not significant (based on paired $t$-tests $)$ in the lamotrigine $(p=0.563)$ or placebo $(p=0.186)$ groups. The mean exit dose of lamotrigine was $388.9 \pm 22.0 \mathrm{mg}$ per day in the group receiving active medication and the equivalent of $377.3 \pm 51.8 \mathrm{mg}$ per day (based on number of pills dispensed) in the placebo group $(p=0.512)$.

Participants discontinued before week 24 for the following reasons: gastrointestinal symptoms, present before the study, that participants felt became worse (week 2), rash that resolved, problems with recent hair transplant and ear infection (week 12), lack of child care (week 10), dizziness (week 2), worsening of gout symptoms, participant felt study procedures were too time consuming and she was already taking too much medication (week 6), itching around mouth and shoulders (week 4), work schedule conflicts (week 2), chest pain in participant with history of coronary artery disease (week 2) (lamotrigine group); no side effects at last assessment but participant did not return to clinic or return phone calls (week 8), dizziness, tremor, and poor coordination (week 16) (placebo group).

Scores on the RAVLT total words learned in trials 1-5 were in the mildly impaired range in both groups at baseline. In these 20 participants ( $n=8$ lamotrigine, $n=11$ placebo, and $n=1$ missing data) with baseline and at least one postbaseline visit, the exit RAVLT scores were significantly higher $(p=0.028)$ in the lamotrigine group as compared to the placebo group (Table 3 ).

Postbaseline structural MRI data were available for 14 participants ( $n=7$ lamotrigine and $n=7$ placebo). Data at week 24 were not available for 14 participants due to study discontinuation prior to week $24(n=10)$, or claustrophobic reaction due to MRI scanner environment, body habitus too large for the scanner, or excessive motion during imaging $(n=4)$. Hippocampal volumes did not differ significantly between groups (Table 4).

Baseline scores on the RAVLT $(n=27)$ correlated significantly with amount of education $(r=0.633$, $p<0.001)$. Baseline left and right hippocampal volume/ TBV ratios $(n=22)$ correlated significantly with each other $(r=0.705, p<0.001)$. In the lamotrigine group, baseline-toexit (week 24) change in left hippocampal volume/TBV ratio 
$(n=7)$ correlated negatively with duration of corticosteroid therapy $(r=-0.868, p=0.011)$, and change in right hippocampal volume/TBV ratio correlated negatively with

Table 2 Demographic Information at Baseline for the Intent-ToTreat Sample $(N=20)$

\begin{tabular}{|c|c|c|c|}
\hline Treatment Group & $\begin{array}{l}\text { Lamotrigine } \\
\qquad(N=9)\end{array}$ & $\begin{array}{l}\text { Placebo } \\
(N=I I)\end{array}$ & $\begin{array}{c}p- \\
\text { value }\end{array}$ \\
\hline Mean age (SD, range) & $44.6(11.2,25-62)$ & $47.4(13.3,24-64)$ & 0.620 \\
\hline Males, N (\%) & $7(77.8)$ & $8(72.7)$ & 0.795 \\
\hline Ethnicity, N (\%) & & & 0.404 \\
\hline Caucasian & $6(66.7)$ & $5(45.5)$ & \\
\hline African-American & $3(33.3)$ & $3(27.3)$ & \\
\hline Hispanic & $0(0)$ & $2(18.2)$ & \\
\hline Other & $0(0)$ & | (9.1) & \\
\hline Education, N (\%) & & & 0.423 \\
\hline $\begin{array}{l}\text { High school, graduation, } \\
\text { or less }\end{array}$ & $4(44.4)$ & $3(27.3)$ & \\
\hline Some college of more & $5(55.6)$ & $8(72.7)$ & \\
\hline $\begin{array}{l}\text { Medical condition requiring } \\
\text { prednisone, } N(\%)\end{array}$ & & & 0.413 \\
\hline Renal transplant & $7(77.8)$ & $10(90.9)$ & \\
\hline Rheumatic disease & $2(22.2)$ & | (9.1) & \\
\hline $\begin{array}{l}\text { Current prednisone dose } \\
\text { (mg per day) }\end{array}$ & $18.4(13.4)$ & I0.1 (3.6) & 0.103 \\
\hline $\begin{array}{l}\text { Duration of prednisone } \\
\text { therapy (months) }\end{array}$ & $85.3(97.9)$ & $44.7(4 \mid .7)$ & 0.272 \\
\hline RAVLT total & $37.0(13.2)$ & $39.1(12.2)$ & 0.726 \\
\hline \multicolumn{4}{|l|}{$\begin{array}{l}\text { Hippocampal volume/ } \\
\text { TBV } \times 100\end{array}$} \\
\hline Left & $0.1662(0.0142)$ & $0.1748(0.0122)$ & 0.246 \\
\hline Right & $0.1699(0.0957)$ & $0.1800(0.0225)$ & 0.297 \\
\hline \multicolumn{4}{|l|}{ Concomitant medications } \\
\hline $\begin{array}{l}\text { Number of } \\
\text { medications/patient }\end{array}$ & $5.11(2.37)$ & $4.91(2.34)$ & 0.851 \\
\hline $\begin{array}{l}\text { Any change in a } \\
\text { concomitant medication }\end{array}$ & $5 / 9(56 \%)$ & 4/II (36\%) & 0.391 \\
\hline
\end{tabular}

Abbreviations: RAVLT, Rey Auditory Verbal Learning Test; SD, standard deviation; TBV, total brain volume. age $(r=-0.773, p=0.042)$. Change in $\operatorname{RAVLT}(n=8)$ also correlated negatively with age $(r=-0.750, p=0.032)$ in the lamotrigine group. In the placebo group, changes in left and right hippocampal volume/TBV ratios $(n=7)$ correlated with each other $(r=0.954, p=0.001)$, and change in RAVLT $(n=11)$ correlated negatively with age $(r=-0.616$, $p=0.044)$.

\section{DISCUSSION}

The hippocampus is sensitive to the effects of corticosteroids. Unlike dexamethasone, which appears to penetrate the CNS rather slowly, prednisolone (De Kloet and McEwen, 1976), the active metabolite of prednisone, readily crosses the blood-brain barrier (Bannwarth et al, 1997). We previously reported improvement in declarative memory in patients receiving long-term corticosteroid therapy who were given open-label lamotrigine (Brown et al, 2003). Our current study attempted to replicate these findings using a randomized, double-blind, placebo-controlled design.

Baseline RAVLT scores were in the mildly impaired range in the patient sample. In the lamotrigine group, RAVLT scores increased to the average range while scores in the placebo group remained mildly impaired. Our data suggest that lamotrigine was associated with statistically significant improvement in declarative memory in patients receiving long-term corticosteroid therapy. The observed change in RAVLT scores with lamotrigine seems to confirm our previous findings. To our knowledge, data are not available relating to functional change with degree of change in the RAVLT. However, the categorical improvement, in the lamotrigine group, from the mildly impaired to average range suggests that the findings may be of clinical as well as statistical significance. Of note, the RAVLT mean actually decreased from baseline to week 12 but then increased by week 24 in the lamotrigine group. This decrease at week 12 appears to be due to one participant with a RAVLT T-score of 6 at week 12. The next lowest RAVLT score by any participant at any assessment was 20. If this participant is excluded the mean at week 12 for the lamotrigine group is $40.0 \pm 8.6$, which is slightly higher than the baseline mean.

Significant changes in hippocampal volume were not observed. The changes in hippocampal volume, not unexpectedly during the 24 -week assessment period, were small in both groups. To our knowledge this is the first study that has looked at the impact of a medication on hippocampal volume in a group of patients exposed to high levels of corticosteroids. Prior studies have looked at

Table 3 Mean RAVLT Scores at Baseline, Week 12, Week 24 and Exit (Includes Subjects that Dropped Out Prior to Week 24) in Patients Receiving Corticosteroids and Given Lamotrigine or Placebo

\begin{tabular}{lccc}
\hline Treatment Group & $\begin{array}{c}\text { Baseline } \\
\text { (Mean } \pm \text { SD) }\end{array}$ & $\begin{array}{c}\text { Week I2 } \\
\text { (Mean } \pm \text { SD) }\end{array}$ & $\begin{array}{c}\text { Week 24 }_{\text {Exit }^{\mathrm{a}}} \\
\text { (Mean } \pm \text { SD) }\end{array}$ \\
\hline Lamotrigine & $37.0 \pm 13.2$ & $35.8 \pm 14.4$ & $46.1 \pm 15.0$ \\
Placebo & $39.1 \pm 12.2$ & $38.5 \pm 10.8$ & $40.1 \pm 11.0$
\end{tabular}

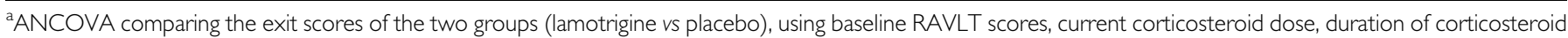
therapy, and years of education as covariates and gender as a fixed factor, with $B$ (difference in adjusted means) $=-10.63,95 \%$ confidence interval (based on difference in adjusted means $)=(-19.90,-1.35)$, d.f. $=1, F=6.13, p=0.028$. 
Table 4 Baseline and Exit Right and Left Hippocampal Volumes in Participants Receiving Corticosteroid Therapy Given Lamotrigine or Placebo

\begin{tabular}{lccccc}
\hline & \multicolumn{2}{c}{ Baseline } & & Week 24* \\
\cline { 2 - 3 } & $\begin{array}{c}\text { Lamotrigine } \\
\text { (Mean } \pm \text { SD) }\end{array}$ & $\begin{array}{c}\text { Placebo } \\
\text { (Mean } \pm \text { SD) }\end{array}$ & & $\begin{array}{c}\text { Lamotrigine } \\
\text { (Mean } \pm \text { SD) }\end{array}$ & $\begin{array}{c}\text { Placebo } \\
\text { (Mean } \pm \text { SD) }\end{array}$ \\
\hline $\begin{array}{l}\text { Right hippocampal/total brain } \\
\text { volume } \times 100\end{array}$ & $0.1691 \pm 0.0096$ & $0.1800 \pm 0.0225$ & & $0.1704 \pm 0.0184$ & $0.1798 \pm 0.0202$ \\
$(+0.8 \%$ from baseline $)$ & $(-0.1 \%$ from baseline $)$ \\
$\begin{array}{l}\text { Left hippocampal/total brain } \\
\text { volume } \times 100\end{array}$ & $0.1662 \pm 0.0142$ & $0.1748 \pm 0.0127$ & & $0.1654 \pm 0.0163$ & $0.1723 \pm 0.0160$ \\
& & & $(-0.5 \%$ from baseline $)$ & $(-1.4 \%$ from baseline $)$ \\
\hline
\end{tabular}

aNCOVA comparing the exit scores of the two groups (lamotrigine vs placebo), baseline hippocampal volume, current prednisone dose, duration of corticosteroid

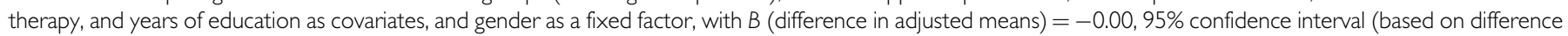
in adjusted means $)=(0.00,0.00)$, d.f. $=I, F=0.036, p=0.852$.

cognitive and hippocampal volume changes in patients with Cushing's disease before and after treatment of the hypercortisolemia. Adults with Cushing's disease demonstrate improvement in some, but not all, cognitive domains following normalization of cortisol levels (Hook et al, 2007). An increase in hippocampal volume of approximately $3 \%$ is reported 17 months after surgical excision of the ACTHsecreting tumor in patients with Cushing's disease (Starkman et al, 1999, 2003). Some, but not all, neurocognitive assessments showed correlations with change in hippocampal volume in Cushing's disease patients (Starkman et al, 2003). In children with Cushing's disease, no changes in a declarative memory task were observed, and some other cognitive measures actually worsened 1 year following treatment (Merke et al, 2005). Hippocampal volume increased by about $5 \%$ in these patients at 1 -year followup $(p=0.08)$. Our study may have failed to observe a significant change in hippocampal volume due to the observation period of only 24 weeks as compared to $12-17$ months in the studies of patients with Cushing's disease.

The negative correlation between change in left hippocampal volume and duration of corticosteroid therapy in the lamotrigine group suggests that patients with longer corticosteroid exposure continued to show a decline in hippocampal volume. In the lamotrigine group, change in right hippocampal volume and change in RAVLT both correlated negatively with age. A similar negative relationship between age and change in RAVLT scores was observed in the placebo group. These findings suggest that older age is associated with further decline in RAVLT scores in both groups, and is consistent with literature suggesting greater sensitivity of the aging hippocampus to corticosteroid effects in animal models (Hassan et al, 1996). The correlational data from our study suggest that future research should target the use of lamotrigine in younger patients with relatively brief duration of corticosteroid therapy.

The study has several limitations. The sample size is modest which may increase the risk of Type I error for memory and Type II error for hippocampal volume. The assessment period of only 24 weeks or less is also a limitation. Changes in hippocampal volume may take a longer period of time to observe. The changes in memory might also increase more with longer treatment. The patient population is complex with serious medical illnesses, multiple concomitant medications, and differences in corticosteroid dose and duration. This limitation is inherent in human research on the long-term effects of corticosteroids. However, the two treatment groups were similar demographically and we controlled for potentially important patient characteristics (eg corticosteroid dose) in the data analysis. The study, while showing improvement in declarative memory, does not prove that the memory improvement was related to an interaction with the corticosteroids. In patients with seizures, lamotrigine appears to have a more benign effect on cognition than some other antiseizure medications (Pressler et al, 2006). In healthy controls (Aldenkamp et al, 2002) and in animal models (Shannon and Love, 2004) lamotrigine appears to be associated with no significant changes in cognitive performance. In patients with bipolar disorder, both improvement (Daban et al, 2006) and worsening of cognitive performance (Osuji et al, 2007, in press) have been reported with lamotrigine. A study in HIV-positive patients with cocaine use reported no change in RAVLT performance with lamotrigine (Margolin et al, 1998). Thus, while the effects of lamotrigine on memory may not be specific to patients taking corticosteroids, studies in other populations suggest neutral or mixed effects of lamotrigine on cognition. The differential dropout rate between treatment groups is a concern and could lead to bias if this is not a random occurrence. Early dropouts and the subjects used in the analysis (intent-to-treat sample) were similar demographically as were the two treatment groups. The higher discontinuation rate in the lamotrigine group may suggest poor tolerability using the dosing and titration schedule employed in this study. Thus, our findings are only generalizable to the subgroup of corticosteroid-treated patients who are able to remain on lamotrigine therapy for at least 12 weeks.

In summary, lamotrigine was associated with improvement in declarative memory potentially consistent with partial reversal of the effects of corticosteroids on hippocampal functioning. Additional research with a longer assessment period is needed to determine if declarative memory continues to improve with lamotrigine compared to placebo and whether differences in hippocampal volume are observed. 


\section{ACKNOWLEDGEMENTS}

This study was supported by NIH grant MH01725 and an investigator-initiated grant from GlaxoSmithKline.

\section{DISCLOSURE/CONFLICTS OF INTEREST}

ES Brown reported having research grants from NIAAA, Stanley Medical Research Institute, AstraZeneca, Forest Laboratories, GlaxoSmithKline, UCB Pharma, and McNeil. MU Shad is on the speaker panel for Bristol-Myers Squibb and Pfizer and has an investigator-initiated trial sponsored by Eli Lilly. IJ Osuji has funding from the National Alliance for Research on Schizophrenia and Depression. M Vazquez and J Wolfshohl reported no financial interests or potential conflicts of interest.

\section{REFERENCES}

Aldenkamp AP, Arends J, Bootsma HP, Diepman L, Hulsman J, Lambrechts D et al (2002). Randomized double-blind parallelgroup study comparing cognitive effects of a low-dose lamotrigine with valproate and placebo in healthy volunteers. Epilepsia 43: 19-26.

Bannwarth B, Schaeverbeke T, Pehourcq F, Vernhes JP, D’Yvoire MB, Dehais J (1997). Prednisolone concentrations in cerebrospinal fluid after oral prednisone. Preliminary data. Revue $d u$ Rhumatisme 64: 301-304.

Bender BG, Lerner JA, Kollasch E (1988). Mood and memory changes in asthmatic children receiving corticosteroids. $\mathrm{J} \mathrm{Am}$ Acad Child Adolesc Psychiatry 27: 720-725.

Brown ES, Beard L, Frol AB, Rush AJ (2006). Effect of two prednisone exposures on mood and declarative memory. Neurobiol Learn Mem 86: 28-34.

Brown ES, Frol A, Bobadilla L, Nejtek VA, Perantie DC, Dhillon H (2003). Effect of lamotrigine on mood and cognition in patients receiving chronic exogenous corticosteroids. Psychosomatics 44: 204-208.

Brown ES, Woolston J, Frol A, Bobadilla L, Khan DA, Hanczyc M et al (2004). Hippocampal volume, spectroscopy, cognition, and mood in patients receiving corticosteroid therapy. Biol Psychiatry 55: 538-545.

Conrad CD, Galea LAM, Kuroda Y, McEwen BS (1996). Chronic stress impairs rat spatial memory on the Y maze, and this effect is blocked by tianeptine pretreatment. Behav Neurosci 110: 1321-1334.

Cook MJ, Fish DR, Shorvon SD, Straughan K, Stevens JM (1992). Hippocampal volumetric and morphometric studies in frontal and temporal lobe epilepsy. Brain 115: 1001-1015.

Daban C, Martinez-Aran A, Torrent C, Sanchez-Moreno J, Goikolea JM, Benabarre A et al (2006). Cognitive functioning in bipolar patients receiving lamotrigine: preliminary results. J Clin Psychopharmacol 26: 178-181.

De Kloet ER, McEwen BS (1976). Differences between cytosol receptor complexes with corticosterone and dexamethasone in hippocampal tissue from rat brain. Biophysica Acta 421: 124-132.

de Quervain DJ, Roozendaal B, Nitsch RM, McGaugh JL, Hock C (2000). Acute cortisone administration impairs retrieval of longterm declarative memory in humans. Nat Neurosci 3: 313-314.

Duvernoy HM (1999). The Human Brain: Surface Three-Dimensional Sectional Anatomy with MRI, and Blood Supply 2nd edn. Springer: New York.

Duvernoy HM (2005). The Human Hippocampus: Functional Anatomy Vascularization and Serial Sections with MRI 3rd edn. Springer: New York.
First MB, Spitzer RL, Gibbon M, Williams JBW (1995). Structured Clinical Interview for DSM-IV Axis I Disorders (SCID-I). Clinician Version. American Psychiatric Press: New York.

Gilbert AR, Rosenberg DR, Harenski K, Spencer S, Sweeney JA, Keshavan MS (2001). Thalamic volumes in patients with firstepisode schizophrenia. Am J Psychiatry 158: 618-624.

Hajek T, Kopecek M, Preiss M, Alda M, Hoschl C (2006). Prospective study of hippocampal volume and function in human subjects treated with corticosteroids. Eur Psychiatry 21: 123-128.

Hassan AH, von Rosenstiel P, Patchev VK, Holsboer F, Almeida OF (1996). Exacerbation of apoptosis in the dentate gyrus of the aged rat by dexamethasone and the protective role of corticosterone. Exp Neurol 140: 43-52.

Hook JN, Giordani B, Schteingart DE, Guire K, Giles J, Ryan K et al (2007). Patterns of cognitive change over time and relationship to age following successful treatment of Cushing's disease. J Int Neuropsychol Soc 13: 21-29.

Keshavan MS, Dick E, Mankowski I, Harenski K, Montrose DM, Diwadkar V et al (2002). Decreased left amygdala and hippocampal volumes in young offspring at risk for schizophrenia. Schizophr Res 58: 173-183.

Khiat A, Yared Z, Bard C, Lacroix A, Boulanger Y (2001). Longterm brain metabolic alterations in exogenous Cushing's syndrome as monitored by proton magnetic resonance spectroscopy. Brain Res 911: 134-140.

Leverenz JB, Wilkinson CW, Colasurdo EA, Raskind MA, Peskind ER (2003). Cerebrospinal Fluid Corticosteroid Levels and Hippocampal Volume and Neuronal Number in Aged Nonhuman Primates Abstract Presented at the International Society of Psychoneuroendocrinology (ISPNE) Thirty-fourth Annual Meeting. New York, NY.

Leverenz JB, Wilkinson CW, Wamble M, Corbin S, Grabber JE, Raskind MA et al (1999). Effect of chronic high-dose exogenous cortisol on hippocampal neuronal number in aged nonhuman primates. J Neurosci 19: 2356-2361.

Lucassen PJ, Muller MB, Holsboer F, Bauer J, Holtrop A, Wouda J (2001). Hippocampal apoptosis in major depression is a minor event and absent from subareas at risk for glucocorticoid overexposure. Am J Pathology 158: 453-468.

Luine V, Villegas M, Martinez C, McEwen BS (1994). Repeated stress causes reversible impairments of spatial memory performance. Brain Res 63: 167-170.

Lupien SJ, McEwen BS (1997). The acute effects of corticosteroids on cognition: integration of animal and human model studies. Brain Res Rev 24: 1-27.

Magariños AM, Deslandes A, McEwen BS (1999). Effects of antidepressants and benzodiazepine treatments on the dendritic structure of CA3 pyramidal neurons after chronic stress. Eur J Pharmacol 371: 113-222.

Magariños AM, McEwen BS (1995). Stress-induced atrophy of apical dendrites of hippocampal CA3c neurons: involvement of glucocorticoid secretion and excitatory amino acid receptors. Neuroscience 69: 89-98.

Magariños AM, McEwen BS, Flugge G, Fuchs E (1996). Chronic psychosocial stress causes apical dendritic atrophy of hippocampal CA3 pyramidal neurons in subordinate tree shrews. J Neurosci 16: 3534-3540.

Magariños AM, Verdugo JMG, McEwen BS (1997). Chronic stress alters synaptic terminal structure in hippocampus. Proc Natl Acad Sci USA 94: 14002-14008.

Magnotta VA, Harris G, Andreasen NC, O'Leary DS, Yuh WT, Heckel D (2002). Structural MR image processing using the BRAINS2 toolbox. Comput Med Imaging Graph 26: 251-264.

Margolin A, Avants SK, DePhilippis D, Kosten TR (1998). A preliminary investigation of lamotrigine for cocaine abuse in HIV-seropositive patients. Am J Drug Alcohol Abuse 24: 85-101. 
Mauri M, Sinforiani E, Bono G, Vignati F, Berselli ME, Attanasio R et al (1993). Memory impairment in Cushing's disease. Acta Neurol Scand 87: 52-55.

Merke DP, Giedd JN, Keil MF, Mehlinger SL, Wiggs EA, Holzer S et al (2005). Children experience cognitive decline despite reversal of brain atrophy one year after resolution of Cushing syndrome. J Clin Endocrinol Metab 90: 2531-2536.

Newcomer JW, Selke G, Melson AK, Hershey T, Craft S, Richards K et al (1999). Decreased memory performance in healthy humans induced by stress-level cortisol treatment. Arch Gen Psychiatry 56: 527-533.

Osuji IJ, Tucker E, Brown ES (2007). Declarative memory in patients with bipolar disorder and stimulant abuse given lamotrigine. J Dual Diagn (in press).

Pisani A, Bonsi P, Martella G, De Persis C, Costa C, Pisani F et al (2004). Intracellular calcium increase in epileptiform activity: modulation by levetiracetam and lamotrigine. Epilepsia 45: 719-728.

Pressler RM, Binnie CD, Coleshill SG, Chorley GA, Robinson RO (2006). Effect of lamotrigine on cognition in children with epilepsy. Neurology 66: 1495-1499.

Remy S, Urban BW, Elger CE, Beck H (2003). Anticonvulsant pharmacology of voltage-gated $\mathrm{Na}+$ channels in hippocampal neurons of control and chronically epileptic rats. Eur J Neurosci 17: 2648-2658.

Rogawski MA, Loscher W (2004). The neurobiology of antiepileptic drugs. Nat Rev Neurosci 5: 553-564.

Sapolsky RM, Uno H, Rebert CS, Finch CE (1990). Hippocampal damage associated with prolonged glucocorticoid exposure in primates. J Neurosci 10: 2897-2902.

Schmidt M (1996). Rey Auditory Verbal Learning Test: A Handbook. Western Psychological Services: Los Angeles, CA.

Shad MU, Muddasani S, Keshavan MS (2006). Prefrontal subregions and dimensions of insight in first-episode schizophrenia - a pilot study. Psychiatry Res 146: 35-42.

Shad MU, Muddasani S, Prasad K, Sweeney JA, Keshavan MS (2004). Insight and prefrontal cortex in first-episode schizophrenia. Neuroimage 22: 1315-1320.

Shannon HE, Love PL (2004). Effects of antiepileptic drugs on working memory as assessed by spatial alternation performance in rats. Epilepsy Behav 5: 857-865.

Shenton ME, Dickey CC, Frumin M, McCarley RW (2001). A review of MRI findings in schizophrenia. Schizophr Res 49: $1-52$.
Shenton ME, Gerig G, McCarley RW, Szekely G, Kikinis R (2002). Amygdala-hippocampal shape differences in schizophrenia: the application of $3 \mathrm{D}$ shape models to volumetric $\mathrm{MR}$ data. Psychiatry Res 115: 15-35.

Sitges M, Chiu LM, Guarneros A, Nekrassov V (2007). Effects of carbamazepine, phenytoin, lamotrigine, oxcarbazepine, topiramate and vinpocetine on $\mathrm{Na}+$ channel-mediated release of $\left[{ }^{3} \mathrm{H}\right]$ glutamate in hippocampal nerve endings. Neuropharmacology 52: 598-605.

Starkman MN, Gebarski SS, Berent S, Schteingart DE (1992). Hippocampal formation volume, memory dysfunction, and cortisol levels in patients with Cushing's syndrome. Biol Psychiatry 32: 756-765.

Starkman MN, Giordani B, Gebarski SS, Berent S, Schork MA, Schteingart DE (1999). Decrease in cortisol reverses human hippocampal atrophy following treatment of Cushing's disease. Biol Psychiatry 46: 1595-1602.

Starkman MN, Giordani B, Gebarski SS, Schteingart DE (2003). Improvement in learning associated with increase in hippocampal formation volume. Biol Psychiatry 53: 233-238.

Starkman MN, Schteingart DE (1981). Neuropsychiatric manifestations of patients with Cushing's syndrome. Arch Intern Med 141: 215-219.

Stefani A, Spadoni F, Bernardi G (1997). Differential inhibition by riluzole, lamotrigine, and phenytoin of sodium and calcium currents in cortical neurons: implications for neuroprotective strategies. Exp Neurol 147: 115-122.

Uno H, Eisele S, Sakal A, Shelton S, Baker E, DeJesus O et al (1994). Neurotoxicity of glucocorticoids in the primate brain. Horm Behav 28: 336-348.

Uno H, Tarara R, Else JG, Suleman MA, Sapolsky RM (1989). Hippocampal damage associated with prolonged and fatal stress in primates. J Neurosci 9: 1705-1711.

Vyas A, Mitra R, Shankaranarayana Rao BS, Chattarji S (2002). Chronic stress induces contrasting patterns of dendritic remodeling in hippocampal and amygdaloid neurons. J Neurosci 22: 6810-6818.

Wang SJ, Sihra TS, Gean PW (2001). Lamotrigine inhibition of glutamate release from isolated cerebrocortical nerve terminals (synaptosomes) by suppression of voltage-activated calcium channel activity. Neuroreport 12: 2255-2258.

Watanabe Y, Gould E, Daniels DC, Cameron H, McEwen BS (1992). Tianeptine attenuates stress-induced morphological changes in the hippocampus. Eur J Pharmacol 222: 157-162. 